\title{
Orçamento de capital: um caso especial de sequenciação de projetos
}

\section{Capital budgeting: a special case of project scheduling}

\author{
Eder Oliveira Abensur ${ }^{1}$
}

\begin{abstract}
Resumo: A gestão de orçamento de capital compreende a organização, análise e escolha de projetos de investimentos criados pelas empresas. Estes projetos podem incluir a atualização da infraestrutura física, renovação do parque de informática ou o desenvolvimento de novos produtos, portanto, caracteriza-se como uma atividade essencial para a sobrevivência e competitividade empresarial. Os objetivos deste trabalho foram: (i) propor um modelo matemático num caso especial em que os gestores podem estabelecer a sequência de execução de projetos, previamente selecionados, que minimiza a necessidade de investimento e (ii) desenvolver uma ferramenta computacional de busca das soluções baseada na integração da Teoria de Opções Reais e em método heurístico com uma nova proposta de busca local denominada de DOP. Apesar da relevância do assunto, verificou-se uma escassez de trabalhos sobre sequenciação de projetos de investimento na literatura. Os testes realizados sobre várias amostras de projetos mostram que o modelo proposto apresentou resultados relevantes de redução de custos quando comparados a procedimentos convencionais de orçamento de capital.
\end{abstract}

Palavras-chave: Análise de investimentos. Finanças. Heurística.

\begin{abstract}
The management of capital budgeting includes the organization, analysis, and choice of investment projects developed by companies. These projects may include, for instance, upgrading the physical infrastructure, modernizing the information technology, or new product development; therefore, they are essential for the survival and competitiveness of businesses. The purposes of this study were: (i) to propose a mathematical model for a special case in which the managers can establish the execution sequence of previously selected projects minimizing investments, and (ii) to develop a computational tool based on the integration of Real Options and heuristic with a new proposal for local search called DOP. Despite the great importance of this subject, there is a lack of research on sequencing of investment projects in the literature. The tests performed on several samples of projects indicate that the model proposed showed significant cost reduction results when compared to those of conventional capital budgeting procedures.
\end{abstract}

Keywords: Investment analysis. Finance. Heuristic.

\section{Introdução}

Apesar da crise dos mercados internacionais iniciada em setembro de 2008, as empresas brasileiras continuam a registrar expressivos investimentos em vários segmentos econômicos. A Companhia Vale do Rio Doce (2013) apresentou, em 2012, um orçamento de R $\$ 13$ bilhões. O Itaú Unibanco (2013), no mesmo ano, apontou investimentos de $\mathrm{R} \$ 3$ bilhões. A BRF Brasil Foods (2013), resultado da fusão entre Perdigão e Sadia, mostrou investimentos de R \$ 2,5 bilhões. Os orçamentos de capital representaram $40 \%$ acima do lucro líquido da Companhia Vale do Rio Doce, $22 \%$ do lucro líquido do Itaú Unibanco (2013) e 83\% acima do lucro líquido da BRF Brasil Foods (2013).

O orçamento de capital é uma delineação de investimentos planejados em ativos fixos, e o processo de orçamento de capital é o processo completo da análise de projetos e da decisão de quais incluir no orçamento de capital (BRIGHAM; GAPENSKI; EHRHARDT, 2001).

Os gastos de capital são realizados por muitos motivos. Os principais são a ampliação (aumento do nível de operações), substituição (reposição ou troca de ativos obsoletos ou desgastados), renovação (reconstrução ou reforma de ativo imobilizado) ou outros (desembolsos de propaganda, consultorias de gestão) (GITMAN; MADURA, 2003).

Investimento e financiamento são atividades gêmeas conectadas por um propósito comum: a criação de valor para a empresa. Elas são decisões conjuntas e mutuamente dependentes. A primeira direciona os recursos enquanto que a segunda procura obter os fundos necessários sem prejudicar a liquidez (caixa)

\footnotetext{
${ }^{1}$ Centro de Engenharia, Modelagem e Ciências Sociais Aplicadas - CECS, Universidade Federal do ABC - UFABC, CEP 09210-170, Santo André, SP, Brasil, e-mail: eder.abensur@ufabc.edu.br
} 
da empresa. Esta visão integrada de investimento e financiamento está em concordância com o conceito de fluxo de caixa livre ao acionista (ABREU FILHO et al., 2006).

A obtenção de fundos nas condições mais favoráveis possíveis para realização dos projetos de investimento é uma das complexas tarefas executadas pelos gestores. Geralmente, o processo de orçamento de capital envolve grandes desembolsos obrigando as empresas a apresentar os recursos financeiros necessários antes do início da execução dos projetos.

É comum, em grandes empresas privadas, o sincronismo entre o orçamento de capital e o ano calendário. Desta forma, o capital necessário aos projetos encontra-se disponível no início de cada ano. Esta prática facilita o controle orçamentário, mas aumenta a pressão pela obtenção dos fundos em tempo hábil.

A tarefa de captação de fundos pode ser facilitada se houver a possibilidade de antecipação de fluxos de caixa de projetos. Estas entradas antecipadas de fluxo de caixa serviriam como capital de giro para os demais projetos reduzindo a necessidade de captação e endividamento das empresas (SOUZA; KLIEMANN NETO; FILOMENA, 2010). Esta alternativa é possível, caso os gestores possam definir a sequência de execução dos projetos selecionados ao longo de um horizonte de planejamento estabelecido.

A experiência profissional do autor, obtida em grandes empresas privadas nacionais e multinacionais, em áreas de desenvolvimento de novos produtos e avaliação de projetos, contribuiu para o esclarecimento e identificação de práticas de orçamento de capital. Entre estas práticas, observou-se com mais frequência o adiamento de projetos. Uma explicação para este fenômeno é apresentada por Kliemann Neto et al. (2011), no contexto da gestão de riscos de projetos de investimento, que reforça o fato de os fluxos de caixa dos projetos serem desenhados a partir de uma realidade diferente daquela na qual ocorrerão.

O propósito primário deste trabalho foi verificar a viabilidade de aplicação de um modelo matemático para suporte às decisões de orçamento de capital de projetos, previamente selecionados, em que é possível definir a sequência de execução, num prazo de tempo definido, que minimize a necessidade de investimento. O modelo matemático desenvolvido, portanto, caracteriza-se como a posteriori. Devido às características do problema estudado, surgiu um objetivo secundário, mas igualmente importante, de desenvolver uma ferramenta computacional baseada em método heurístico para busca e avaliação dos resultados.

Para os propósitos deste estudo, procuraram-se, na literatura especializada, projetos selecionados por algum critério técnico (rentabilidade, risco, liquidez) e que pudessem ter seus fluxos de caixa reconstituídos. Para os testes realizados, vinte e um (21) projetos de investimento e seus respectivos fluxos de caixa selecionados pelos métodos de Índice de Lucratividade (IL), Programação de Metas e Programação Multiobjetivo, apresentados por Abensur (2012), foram usados para a formação inicial de três grupos de 5, 9 e 14 projetos. Além destes, outros dezesseis grupos de 2 a 20 projetos foram formados por meio de sorteio aleatório entre os vinte e um projetos participantes, resultando na primeira rodada de simulações (parte 1). Uma segunda rodada de simulações foi feita a partir do sorteio e formação de outros 19 grupos de projetos (parte 2). Ao todo, foram constituídas trinta e oito amostras distintas para execução dos testes. Para a realização das simulações, foi desenvolvido um aplicativo baseado em planilha Excel e na linguagem Visual Basic hospedada no Microsoft Excel@. Usou-se um microcomputador com processador I3 M350 de 2,27 GHz e 4GB de memória RAM.

O trabalho está estruturado da seguinte forma: (i) a seção 2 descreve os fundamentos de análise de investimentos; (ii) a seção 3 explica o método de busca empregado, inserido no contexto de otimização; (iii) a seção 4 mostra a formulação do modelo proposto; (iv) na seção 5, as amostras e os testes aplicados são caracterizados bem como os resultados apresentados; e (v) a seção 6 apresenta as conclusões do estudo.

\section{Análise de investimentos}

Usualmente, os projetos de investimento são representados por séries de entradas líquidas (receitas menos custos) ao longo do horizonte de planejamento que são denominadas de fluxos.

As séries de fluxos de caixa podem ser classificadas como convencionais e não convencionais. Uma série de fluxos de caixa convencionais é formada por um gasto inicial seguido somente por uma série de entradas. Uma série não convencional de fluxos de caixa é aquela na qual um desembolso inicial é seguido por uma série de entradas e saídas (GITMAN; MADURA, 2003).

A maioria das aplicações e análises praticadas em âmbito gerencial está contida na categoria de fluxos de caixa convencional. Os métodos tradicionais de análise de investimentos partem do fluxo de caixa para aplicação de uma taxa de desconto denominando-se, também, como técnicas de fluxo de caixa descontado $(F C D)$. O método do valor presente líquido (VPL), a taxa interna de retorno (TIR) e o payback descontado $(P B D)$ são exemplos clássicos deste tipo. A Figura 1, a seguir, mostra o mecanismo da aplicação do $V P L$ sobre um fluxo de caixa convencional a uma taxa de desconto de $12 \%$ ao período.

A padronização da representação dos projetos de investimento em fluxos de caixa auxilia sua organização e comparação. Uma vez que o portfolio 
de projetos de investimento tenha sido selecionado e havendo a liberdade de sequenciação (antecipação ou adiamento), o problema recai na escolha da ordem de execução dos projetos, visando minimizar o investimento inicial e, consequentemente, o esforço de captação de fundos.

A Figura 2, a seguir, mostra o exemplo de dois projetos hipotéticos com diferentes investimentos iniciais e fluxos de caixa. A sequência apresentada na Figura 2 é o resultado da reordenação dos projetos a partir da data 0 .

$\mathrm{O}$ portfolio $\mathrm{B}$, reordenado à direita da figura, apresenta um investimento total necessário de R \$ 200 compensado pela entrada de $\mathrm{R} \$ 100$ na data 1 , que anula o desembolso de R $\$ 100$ na mesma data. O desembolso de $\mathrm{R} \$ 200$ representa 20\% a menos do investimento do portfolio A, à esquerda da figura, de $\mathrm{R} \$ 250(\mathrm{R} \$ 100+\mathrm{R} \$ 200-\mathrm{R} \$ 50)$ até a data 1 , ou $33 \%$ a menos caso todos os projetos do portfolio $\mathrm{A}$ fossem iniciados na data 0 com necessidade total de $\mathrm{R} \$ 300$ (R\$ 200 + R\$ 100). Este pequeno exemplo demonstra o potencial deste tópico para a gestão empresarial.

O termo sequência ou sequenciação é empregado em muitos campos da ciência. Na engenharia genética, uma sequência de DNA ou sequência genética é uma série que representa a estrutura primária de uma molécula ou cadeia de DNA com capacidade de carregar informação. Na engenharia de produção, a sequenciação envolve a programação de uma série de atividades aplicadas em ordem sobre um recurso produtivo (BAKER; SCUDDER, 1990; BISKUP; FELDMANN, 2001; SABOIA, 2010; TOSO; MORABITO, 2005).

Os problemas de programação e sequenciação surgem em qualquer ambiente em que se deseja definir horários, locais e atividades. No contexto da programação da produção, foram criadas regras de decisão lógica para selecionar uma ordem de produção, dentre as disponíveis, para o processamento em uma máquina que acabou de ficar livre. Essas regras de decisão também são chamadas de regras de despacho.

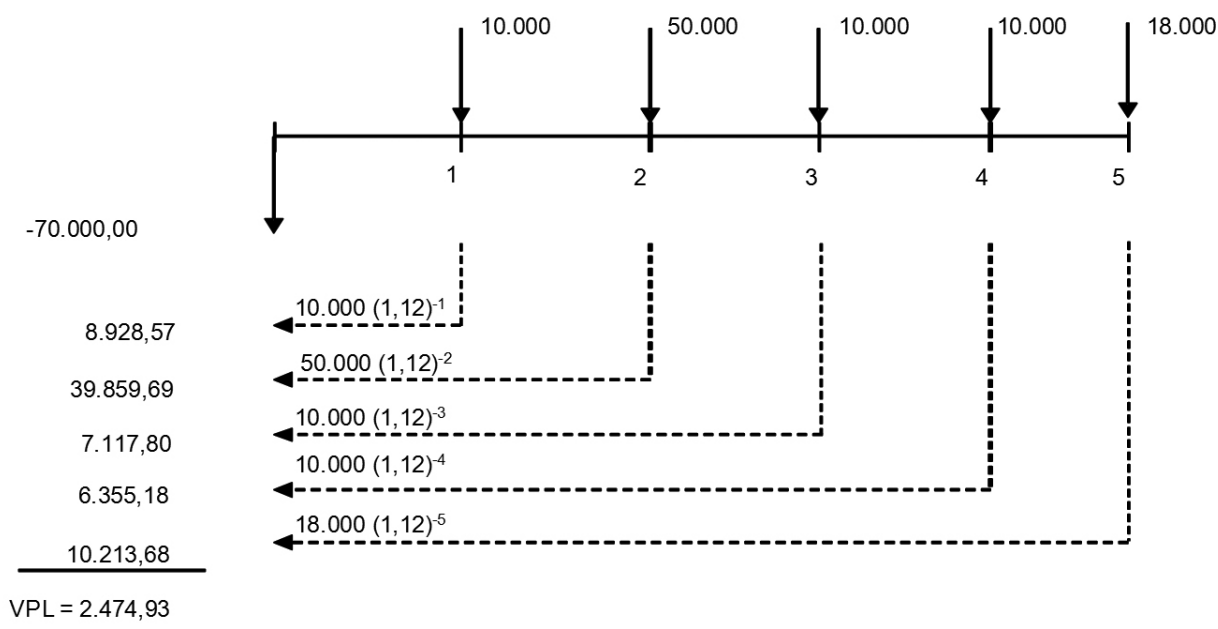

Figura 1. Método do Valor Presente Líquido.

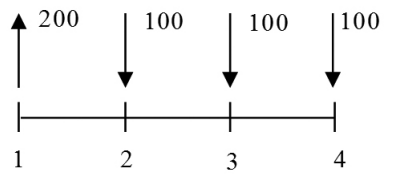

(a)

(b)
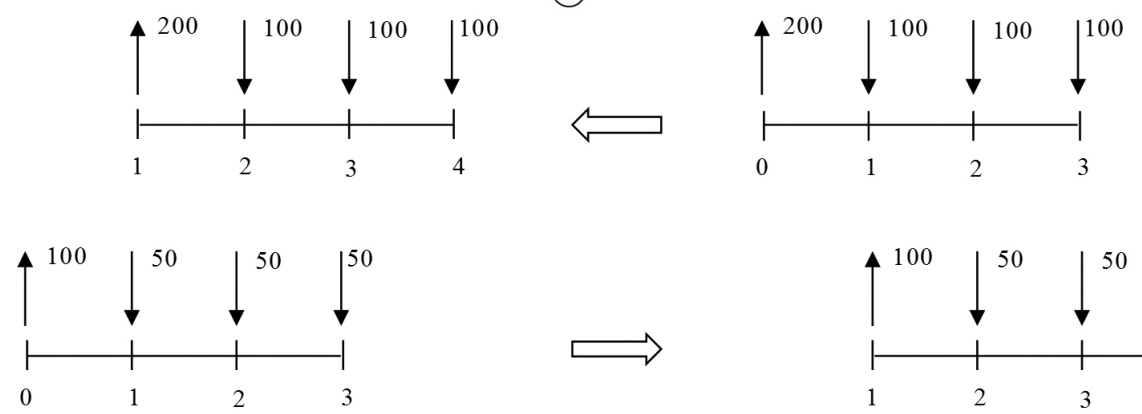

Investimento Total $=250$

Investimento Total $=200$

Figura 2. Fluxo de caixa do portfolio. 
Algumas das mais conhecidas são: (i) SPT (Shortest Processing Time) - sequenciar as ordens de acordo com o menor tempo de processamento; (ii) WSPT (Weighted Shortest Processing Time) - sequenciar as ordens de acordo com a maior razão entre a penalidade de atraso e o tempo de processamento; (iii) $E D D$ (Earliest Due Date) - sequenciar as ordens com a menor data de entrega; e (iv) FIFO (First In First $O u t$ - sequenciar as ordens de acordo com aquela que está há mais tempo disponível para processamento (COLIN, 2007).

Ross, Westerfield e Jaffe (2002) argumentam que, nos métodos de $F C D$, como o VPL, a análise é relativamente estática, enquanto as decisões das empresas estão inseridas num ambiente dinâmico que envolve opções a serem consideradas na avaliação de projetos.

No contexto do problema de orçamento de capital analisado, diferentes sequências de execução do portfolio de projetos proporcionarão diferentes necessidades de captação e a escolha recairá na sequência que fornecerá o menor investimento inicial. Uma fórmula geral para expressar o investimento mínimo $I_{M I N}$ necessário pode ser feita, conforme mostrado simplificadamente a seguir na Equação 1, incorporando-se uma penalidade por atraso $(p)$ na mesma linha lógica dos procedimentos de sequenciação de engenharia de produção. A penalidade $p$ pode refletir o custo financeiro pelo adiamento do fluxo de caixa do projeto ou multas processuais.

$$
I_{M I N}=\left[\sum_{i=1}^{n} \sum_{j=0}^{m} P i j\right]-\left[\sum_{i=1}^{n} p i\right]
$$

Em que:

$P_{i j}=$ entrada líquida do projeto $i$ na data $j$;

$p_{i}=$ penalidade por atraso do projeto $i$;

$n=n^{\circ}$ de projetos;

$m=$ vida útil máxima dos projetos analisados.

\subsection{Teoria de opções reais}

As opções reais consideram as diversas flexibilidades existentes em um projeto com razoável grau de adaptação a situações incertas. Entre as flexibilidades estão: expansão de atividades, adiamento e abandono do investimento.

Conforme Brigham, Gapenski e Ehrhardt (2001), os gestores têm oportunidades de influenciar o resultado de um projeto e responder às mudanças nas condições de mercado e às atitudes dos concorrentes. As chamadas opções reais são diferenciadas das opções financeiras, porque envolvem ativos reais, em lugar de financeiros. Ainda conforme Brigham, Gapenski e Ehrhardt (2001), a opção do tempo oportuno ou do adiamento, geralmente, é mais valiosa para empresas com tecnologia própria, patentes, licenças ou outras barreiras de ingresso.
Segundo Trigeorgis (1993), nas opções reais, o valor do projeto corresponde ao valor presente expandido, que é igual ao valor presente tradicional do projeto (estimado pelo fluxo de caixa tradicional) acrescido do valor das opções reais existentes.

Por esta ótica, a opção de adiamento seria equivalente à penalidade de diferir o fluxo de caixa conforme expresso na Equação 1. O valor desta opção seria dado pela Expressão 2 a seguir (BRIGHAM; GAPENSKI; EHRHARDT, 2001):

Valor da Opção = Novo $V P L-$ Antigo $V P L$

\section{Métodos de busca de soluções}

Esta seção apresenta tradicionais e conhecidas técnicas de busca de soluções inseridas num contexto de otimização. Em algumas situações, são apresentados, como exemplos, problemas clássicos de otimização para facilitar a compreensão da justificativa do método de busca adotado.

De uma forma geral, os problemas de otimização passíveis de programação matemática podem ser divididos em: (i) programação linear, quando a função objetivo e todas as restrições são funções lineares das variáveis de decisão e (ii) programação não linear, em que a função objetivo e/ou pelo menos uma das restrições envolvidas não são funções lineares das variáveis de decisão. Os problemas da categoria de programação linear podem ser ainda divididos em: (i) programação linear contínua, em que as variáveis de decisão podem assumir valores contínuos e (ii) programação linear inteira $(P L I)$, em que as variáveis de decisão podem assumir valores discretos (inteiros). Conforme Goldbarg e Luna (2005), os principais algoritmos de solução dos problemas de PLI são: (i) algoritmos de abordagem exata (enumeração implícita, Branch-and-Bound) e (ii) abordagem heurística.

Enquanto os problemas lineares contínuos possuem no simplex um algoritmo muito eficiente para a solução exata, os problemas lineares inteiros, salvo alguns casos particulares, normalmente carecem da mesma sorte. O cerne da dificuldade da abordagem exata está na explosão combinatória dos métodos enumerativos. Um problema com $n$ variáveis desenvolverá, no mínimo, cerca de $2^{(\mathrm{n}+1) / 2}$ nós (partições do problema principal). Se o problema possuir 201 variáveis, então a árvore será da ordem de $2^{101}$ nós. Um computador capaz de examinar 1,5 trilhões de nós por segundo dessa árvore levaria cerca de 537 milhões de anos para esgotar todas as possibilidades existentes (GOLDBARG; LUNA, 2005).

\subsection{Enumeração implícita ou enumeração exaustiva}

A enumeração é um tipo de método exato, ou seja, é capaz de encontrar a melhor de todas as soluções de 
um problema (solução ótima). O termo enumeração ou enumerar é comumente empregado na programação linear inteira. Ele significa relacionar metodicamente o conjunto de todas as possíveis soluções. Em tese, é possível enumerar todas as combinações de soluções e avaliá-las conforme um objetivo definido. As soluções que produzem os melhores resultados são denominadas de soluções ótimas. Devido ao fato de se testar todas as possibilidades para definição das melhores soluções, é também usada a expressão enumeração exaustiva.

Problemas de roteamento, que envolvem a determinação da rota ou das rotas mais curtas a partir de uma origem até um destino conhecido, podem ser resolvidos por este método. A quantidade de soluções possíveis é, em geral, expressa pelo princípio de contagem da permutação. Como exemplo, o número de rotas (ou circuitos) envolvidas entre quatro cidades que devem ser visitadas exatamente uma vez por um vendedor é igual a $(4-1) !=3 !=6$ (problema do caixeiro-viajante).

De modo geral, a enumeração exaustiva não é prática. No caso do problema do caixeiro-viajante, mesmo um problema de tamanho modesto de 11 cidades exigirá enumerar $10 !=3.628 .800$ circuitos, uma tarefa realmente assustadora (TAHA, 2008).

Além da explosão combinatória, a enumeração das soluções possíveis de um problema pode ser uma tarefa matemática complexa. No caso analisado da sequenciação de projetos de investimento, a avaliação das soluções é feita num prazo de tempo a partir da data mais cedo de início dos projetos também denominada de data 0 . Este prazo define as datas (posições) em que as soluções são pesquisadas. Em qualquer destas datas, há a possibilidade de haver: (i) nenhum projeto; (ii) um projeto; (iii) vários projetos; ou (iv) todos os projetos. Cada uma destas condições define sequências diferentes, dificultando enormemente a tarefa de enumeração.

Para se ter uma noção da citada complexidade matemática, ela pode ser resumida na seguinte pergunta: de quantas formas diferentes $N$ projetos independentes podem ser iniciados em $Z$ datas definidas?

As possibilidades de programação de três projetos independentes $A, B$ e $C$ em $Z$ datas podem ser expressas pelo princípio de contagem da combinação conforme a Expressão geral 3 a seguir. Há, em cada data, a possibilidade de haver: (i) nenhum projeto ( \{\} ); (ii) um projeto ( $\{\mathrm{A}\},\{\mathrm{B}\},\{\mathrm{C}\})$; (iii) dois projetos ( $\{\mathrm{A}, \mathrm{B}\}$, $\{A, C\},\{B, C\})$; ou (iv) todos os três $(\{A, B, C\})$.

$$
\sum_{k=0}^{N} C_{N, k}
$$

Para o exemplo citado de três projetos $(A, B, C)$, tem-se:

$$
\begin{aligned}
& \sum_{k=0}^{3} C_{3, k}=\sum_{k=0}^{3} \frac{n !}{k !(n-k) !}=\frac{3 !}{0 !(3-0) !}+\frac{3 !}{1 !(3-1) !}+ \\
& \frac{3 !}{2 !(3-2) !}+\frac{3 !}{3 !(3-3) !}=1+3+3+1=8
\end{aligned}
$$

A Tabela 1, a seguir, resume as combinações possíveis $(C)$ em cada data em função do número de projetos $(N)$. Pela progressão geométrica apresentada, para 20 projetos, haveria, em cada data, 1.048.576 combinações possíveis!

\subsection{Heurística construtiva e heurística de melhoria}

A análise de desempenho de algoritmos desenvolvida pela ciência da complexidade computacional divide os problemas em duas classes: (i) problemas da classe $P$, ou seja, fáceis, cuja solução ótima pode ser encontrada dentro de um tempo razoável e (ii) problemas da classe $N P$, problemas difíceis, cujos algoritmos de solução conhecidos são baseados em enumeração, quer seja implícita ou não. Nos problemas $N P$, de maneira geral, o número de combinações possível é assustadoramente grande, fazendo com que os algoritmos enumerativos (Branchand-Bound, simplex) não consigam resolver problemas com um grande número de entradas (variáveis) em tempo hábil. Caso o problema pertença à classe difícil, a alternativa disponível é o desenvolvimento de algoritmos que encontrem boas soluções, mas sem a garantia de otimalidade. Aos algoritmos sem a garantia de otimalidade, dá-se o nome de heurísticas (COLIN, 2007).

Uma heurística é uma técnica que busca alcançar uma boa solução, utilizando um esforço computacional considerado razoável, sendo capaz de garantir a viabilidade ou a otimalidade da solução encontrada ou, ainda, em muitos casos, ambas, especialmente nas ocasiões em que essa busca partir de uma solução viável próxima ao ótimo (GOLDBARG; LUNA, 2005).

Tabela 1. Total de combinações.

\begin{tabular}{ccccccccccccc}
\hline \multicolumn{10}{c}{$N$} & \multicolumn{10}{c}{$\boldsymbol{1}$} \\
\hline & 2 & 3 & 4 & 5 & 6 & 7 & 8 & 9 & 10 & 14 & 20 \\
$C$ & 4 & 8 & 16 & 32 & 64 & 128 & 256 & 512 & 1.024 & 16.384 & 1.048 .576 \\
\hline
\end{tabular}

Fonte: Elaborado pelo autor. 
A palavra heurística é originada do grego heuriskein que significa descobrir. A heurística é um procedimento para resolver problemas por meio de uma abordagem intuitiva. Como características principais dos procedimentos heurísticos, destacam-se: o bom desempenho, rapidez e simplicidade. Ela é especialmente indicada quando os métodos exatos são proibitivos por razões de tempo de execução (tempo de processamento), consumo de memória ou tempo de desenvolvimento da solução computadorizada. Os problemas combinatórios, como o analisado neste estudo, estão entre os que podem ser solucionados por heurísticas.

Existem diferentes categorias de heurísticas, de acordo com o modo que buscam e constroem suas soluções. As heurísticas de construção geram uma solução por meio da adição de componentes individuais, um de cada vez, até achar uma solução factível. Devido a sua simplicidade e rapidez, são empregadas para gerar uma solução inicial.

As heurísticas construtivas geram uma solução inicial. Caso ela não seja satisfatória, empregam-se procedimentos de melhoria sobre a solução obtida. Um método com larga aplicação é a busca local ou busca de vizinhança. A partir de uma solução inicial, procura-se em uma certa vizinhança a melhor solução possível e repete-se o processo até que nenhuma melhoria seja obtida. A solução final é denominada de ótimo local, pois ela foi alcançada dentro de uma vizinhança. A desvantagem é que, em geral, não há garantia de que o ótimo local obtido seja ótimo global. A Figura 3, a seguir, resume as classificações dos métodos heurísticos.

O desempenho dos métodos de busca local depende da definição das vizinhanças. Algumas técnicas envolvendo permutações são recomendadas para a construção de vizinhanças, tais como:

a) Troca de pares adjacentes (adjacent pairwise interchange - API)

Há uma troca de pares adjacentes da solução inicial. Dado um conjunto inicial de soluções $x=\{1,2,3,4\}$ as vizinhanças geradas pelo movimento $A P I$ seriam: $\{2,1,3,4\},\{1,3,2,4\}$ e $\{1,2,4,3\}$. O número máximo de combinações é $N(x)=n-1$, em que $n$ é igual ao número de elementos da solução inicial.

b) Dual API (dual adjacent pairwise interchange)

É o resultado de, no máximo, duas trocas adjacentes. Dado um conjunto inicial de soluções $x=\{1,2,3,4\}$, tem-se como vizinhanças geradas pelo movimento Dual API: $\{2,1,4,3\},\{2,1,3,4\},\{2,3,1,4\},\{1,2,4,3\}$, $\{1,4,2,3\},\{1,3,2,4\},\{3,1,2,4\},\{1,3,4,2\}$. O número máximo de combinações é $N(x)=\left(n^{2}+n-4\right) / 2$.

c) Troca de todos os pares (allpairs - AP)

Há uma troca de todos os pares da solução inicial. Dado um conjunto inicial de soluções $x=\{1,2,3,4\}$ as vizinhanças geradas pelo movimento $A P$ seriam: $\{2,1,3,4\},\{3,2,1,4\},\{4,2,3,1\},\{1,3,2,4\},\{1,4,3,2\}$ e $\{1,2,4,3\}$. O número máximo de combinações é $N(x)=n(n-1) / 2$.

Além do caráter combinatório, o problema analisado apresenta características que determinam condições diferenciadas para a construção das vizinhanças. Os projetos apresentam desembolsos iniciais (investimentos) seguidos de entradas líquidas. A princípio, a simples troca de posições entre os inícios dos projetos numa mesma data seria inócua, pois não haveria redução do investimento. A redução do investimento foi investigada por meio do deslocamento dos projetos (desembolso inicial mais entradas líquidas) ao longo do prazo limite de adiamento. A redução amplificada é obtida caso o deslocamento entre pares de projetos seja feito em sentido contrário, conforme foi mostrado na Figura 2.

A proposta deste novo procedimento de definição de vizinhanças adaptado às características dos fluxos de caixa do processo de orçamento de capital foi denominado de deslocamento orientado de pares $(D O P)$.

\section{$4 \mathrm{O}$ modelo proposto}

O modelo proposto segue os fundamentos heurísticos clássicos e está dividido em dois estágios: (i) determinação de uma solução inicial pela aplicação da heurística construtiva e (ii) refinamento da solução inicial pela aplicação da heurística de melhoria. Em cada um dos estágios, o modelo proposto busca

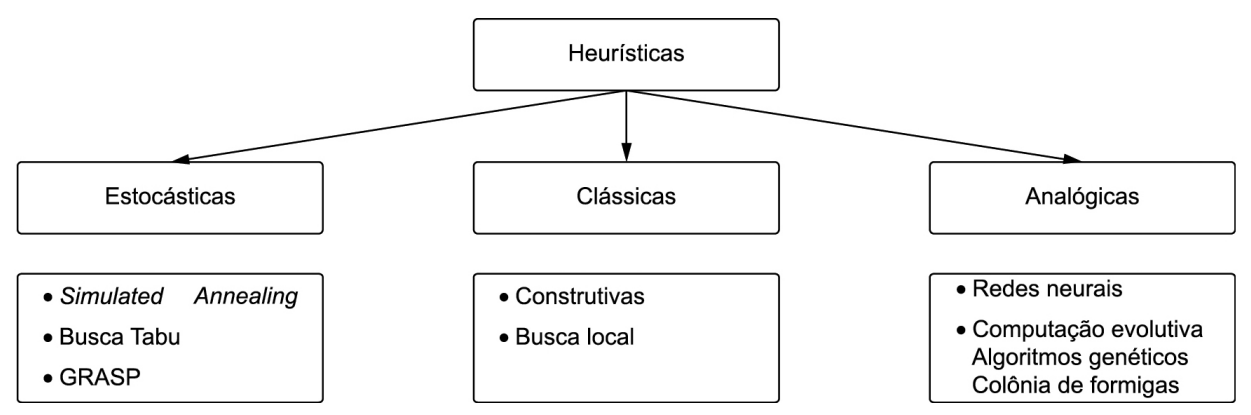

Figura 3. Classificação dos métodos heurísticos. Fonte: Adaptado de Goldbarg e Luna (2005). 
minimizar a função objetivo composta pelos fluxos de caixa dos projetos selecionados para análise, acrescidos, quando assim for necessário, das penalidades de adiamento dos projetos deslocados.

Cada deslocamento imposto sensibilizará a função objetivo. Ao término das iterações, o melhor resultado, ou seja, a sequência de projetos com o menor investimento total encontrado é escolhida.

Além disso, as seguintes premissas foram consideradas:

a) Os projetos analisados foram previamente selecionados por algum critério de escolha e fazem parte do orçamento de capital;

b) Preliminarmente, todos os projetos começam suas atividades na mesma data inicial;

c) A restrição de orçamento de capital ocorre uma única vez na data inicial de análise dos projetos.

d) Os projetos são independentes entre si;

e) São considerados apenas os adiamentos dos projetos;

f) Há um prazo limite de adiamento dos projetos. Para os testes realizados, foram consideradas três datas para pesquisa dos resultados incluindo a data inicial (0);

g) Considerou-se como penalidade ( $p$ ), a opção real de adiamento do projeto avaliado pelo seu $V P L$ conforme a Equação 2;

h) Por conservadorismo, adotou-se a menor TMA dos projetos analisados, em cada amostra, como sendo a taxa de desconto comum (TMA $)$ dos fluxos de caixa para avaliação do valor presente dos resultados.

A função objetivo do modelo matemático proposto é apresentada pela Equação 4 a seguir.

$$
\begin{aligned}
& \min Z=\left[\sum_{i=1}^{n} \sum_{\substack{j=0 \\
p / \forall P_{i j}<0}}^{m} \frac{P_{i j}}{\left(1+T M A_{c}\right)^{j}}\right]-\left[\sum_{i=1}^{n} V P L_{i}\left(1+T M A_{i}\right)^{a_{i}}-V P L_{i}\right] \\
& \text { sujeito a: } \\
& 1 \leq i \leq n \quad n \in\{1,1,2, \ldots . N\} \\
& 0 \leq j \leq m \quad m \in\{0,1,2, \ldots . M\}
\end{aligned}
$$

Em que:

$P_{i j}=$ entrada líquida do projeto $i$ na data $j$;

$N=$ número de projetos analisados;

$M=$ vida útil máxima dos projetos analisados;

$T M A_{c}=$ taxa mínima de atratividade comum usada para análise do $V P L$ dos resultados;

$T M A_{i}=$ taxa mínima de atratividade do projeto $i$;

$a_{i}=$ adiamento do projeto $i$.

Em analogia às heurísticas desenvolvidas para o problema de sequenciação de tarefas em máquinas (BISKUP; FELDMANN, 2001; HOOGEVEEN; VELDE, 1991; KOULAMAS; ANTONY; JAEN, 1994; OSMAN; POTTS, 1989), desenvolveu-se uma heurística construtiva de geração da solução inicial para o problema analisado conforme descrito a seguir: a) O conjunto dos $N$ projetos é classificado em ordem decrescente de investimento inicial.

b) Impõe-se o prazo máximo de adiamento ao projeto de maior investimento inicial. Em caso de empate, dá-se preferência ao projeto com menor entrada líquida após o investimento inicial.

c) O projeto seguinte é antecipado em um período em relação ao projeto anterior (no início do procedimento seria o projeto de maior investimento inicial) até o limite da data mais cedo de início dos projetos (data 0 ).

d) Repete-se o passo anterior para os projetos remanescentes até finalizar a lista.

O procedimento proposto para refinar a solução inicial (heurística de melhoria) foi o deslocamento orientado de pares $(D O P)$, descrito na seção 3.2. Por esse método, cada projeto da solução inicial é selecionado e avaliam-se os deslocamentos contrários dos demais projetos até o limite do prazo máximo de adiamento definido para análise. A cada deslocamento o valor da função objetivo é calculado. O procedimento é encerrado quando todos os projetos forem analisados. Seleciona-se a sequência que proporcionar a menor função objetivo.

\section{Resultados}

A relação dos projetos analisados e seus respectivos fluxos de caixa são apresentados na Tabela 2 a seguir. Quando necessário, recorreu-se às fontes primárias para reconstituição dos fluxos de caixa destacando-se: Abensur (2012), Brigham, Gapenski e Ehrhardt (2001), Hirschfeld (2009) e Samanez (2009). Foi mantida a numeração original dos projetos.

Três heurísticas de melhoria distintas foram desenvolvidas para avaliação e comparação de resultados. A heurística $H \mathrm{H}$ efetua todos os deslocamentos possíveis dos projetos (pares), mas sem ênfase em fazê-los em sentido contrário. A heurística $H 2$ usa o conceito $D O P$ proposto, seleciona um projeto, avalia o afastamento atual deste projeto e efetua o maior deslocamento contrário possível no projeto seguinte. A heurística $H 3$ faz o mesmo que a $H 2$ e, além disso, efetua, gradualmente, todos os deslocamentos contrários possíveis entre os projetos analisados. Os procedimentos são encerrados quando toda a lista de projetos for analisada.

As Tabelas 3 e 4 mostram os melhores resultados encontrados mediante aplicação das heurísticas, respectivamente, na primeira e segunda rodada de simulações. Mediu-se o desempenho em função da redução percentual do investimento e do tempo de execução. A redução percentual foi calculada a partir do investimento original, ou seja, caso todos os projetos iniciassem na data 0 . Todas as heurísticas de melhoria partem da solução inicial gerada pela heurística construtiva $(H C)$, descrita na seção 3.2. 


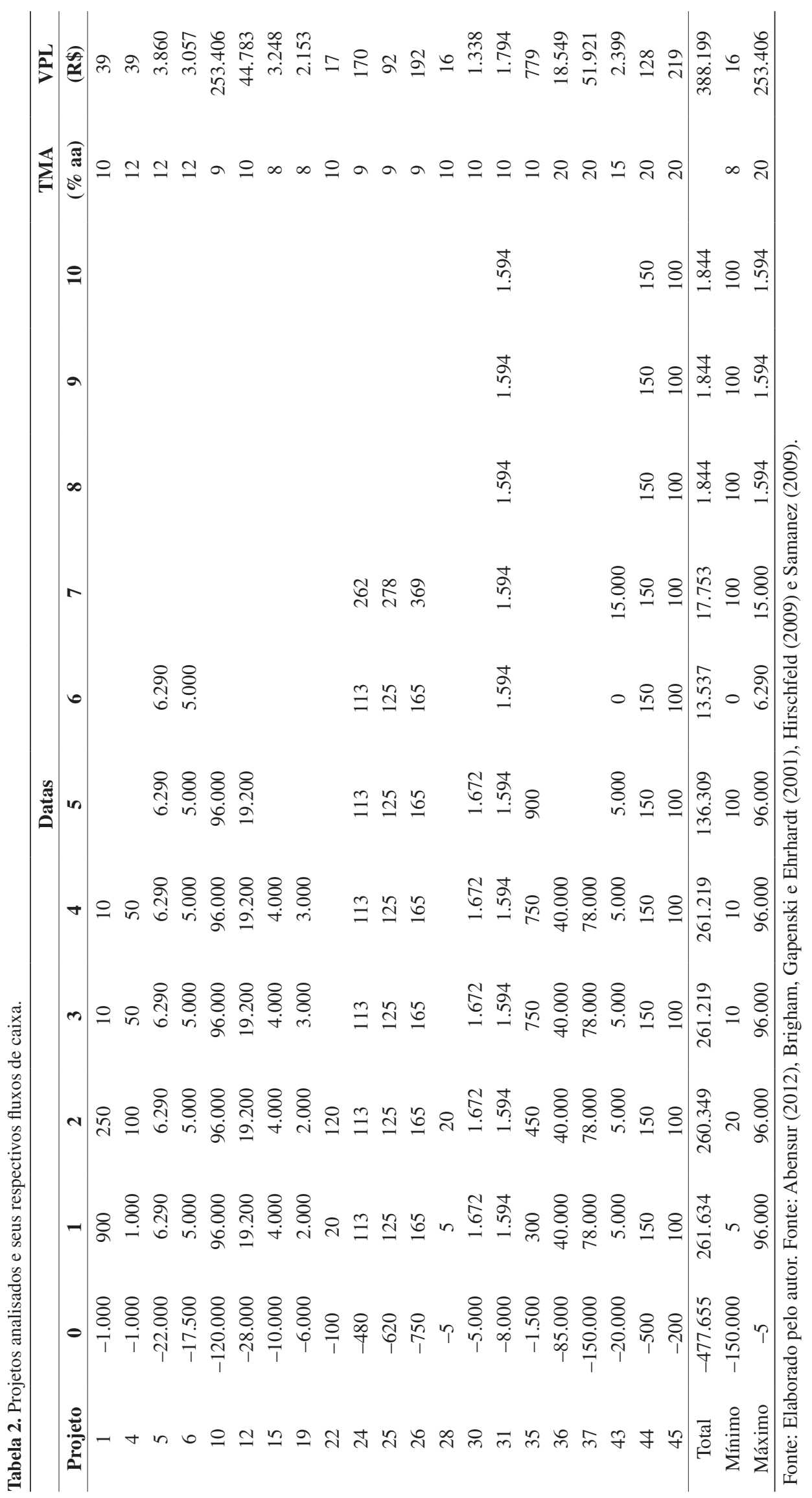




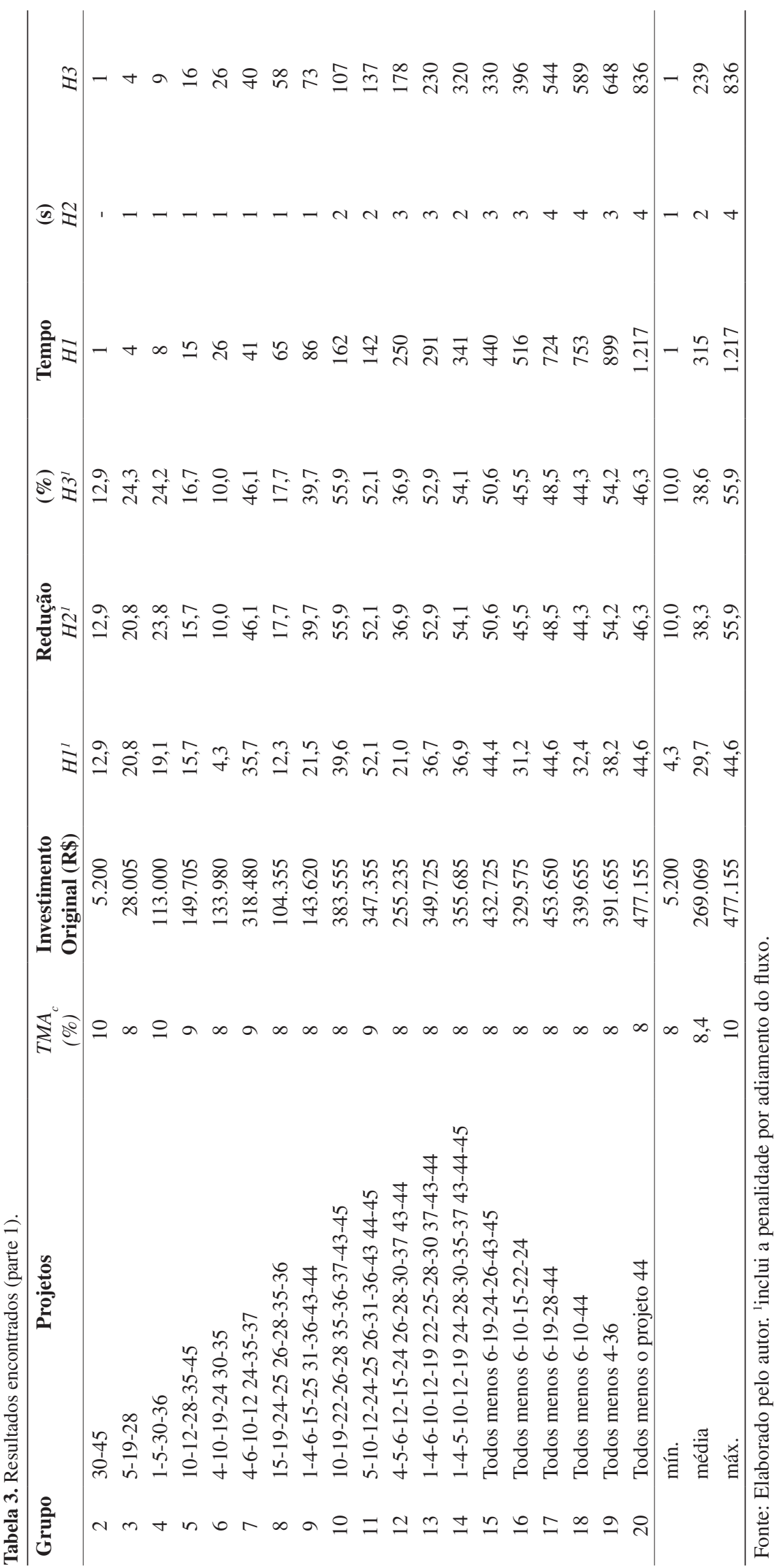




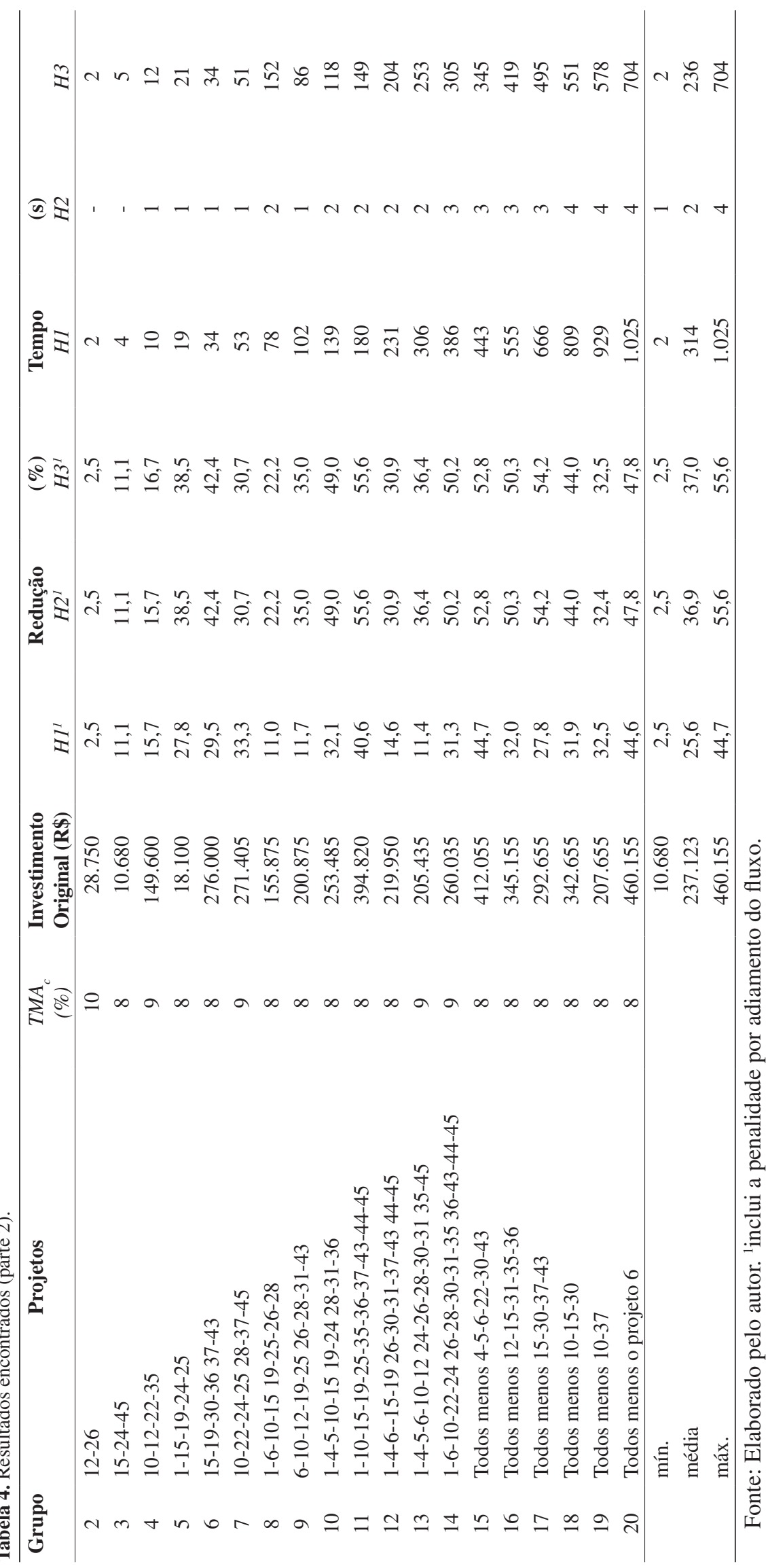


A heurística $H 1$, que não utiliza o conceito $D O P$, apresentou os piores resultados em termos de redução percentual do investimento necessário, número de melhores resultados e em tempo de execução. Em relação ao número dos melhores resultados encontrados, ela obteve apenas seis em trinta e oito ou $15,8 \%$.

O conceito $D O P$ proposto mostrou-se eficiente. As heurísticas $\mathrm{H} 2$ e $\mathrm{H} 3$ atingiram, respectivamente, trinta e três $(86,8 \%)$ e trinta e sete $(97,4 \%)$ dos melhores resultados. Como esperado, a heurística $H 3$, que efetua mais deslocamentos de pares de projetos, obteve a melhor média de redução percentual e o maior número de melhores resultados. O método $H 3$ também obteve os melhores resultados quando comparados aos valores alcançados pelo método exato de enumeração exaustiva executado manualmente sobre as amostras do grupo 2 e 3 (parte 1). A heurística $H 2$ apresentou o melhor desempenho em tempo. A Tabela 5, a seguir, apresenta a sequenciação dos projetos do grupo 20 da parte 1 obtida pela heurística $H 3$.

O desempenho inferior da heurística $H 2$ para as amostras menores pode ser explicado quando o número de projetos for inferior ou igual à quantidade de datas pesquisadas. Nesta situação, as combinações de deslocamentos de pares de projetos feitas a mais pela heurística $H 3$ proporcionam resultados superiores. Entretanto, para as amostras maiores, os resultados entre as duas heurísticas são praticamente equivalentes, mas com um enorme ganho de tempo para a heurística H2.

Desta forma, surge naturalmente a proposta de combinar as duas heurísticas. As amostras com quantidade de projetos inferior às datas pesquisadas seriam simuladas pela heurística $H 3$, enquanto os demais casos seriam executados pela heurística $H 2$. A Figura 4 apresenta o fluxograma resumido da integração das heurísticas $H C, H 2$ e $H 3$. A Tabela 5

Tabela 5. Sequenciação dos projetos do grupo 20 (parte 1).

\begin{tabular}{cccccccccccc}
\hline $\mathbf{0}$ & $\mathbf{1}$ & $\mathbf{2}$ & $\mathbf{3}$ & $\mathbf{4}$ & $\mathbf{5}$ & $\mathbf{6}$ & $\mathbf{7}$ & $\mathbf{8}$ & $\mathbf{9}$ & $\mathbf{1 0}$ & $\mathbf{1 1}$ \\
\hline \multirow{4}{*}{120.000} & & -150.000 & 78.000 & 78.000 & 78.000 & 78.000 & & & & & \\
& 96.000 & 96.000 & 96.000 & 96.000 & 96.000 & & & & & & \\
& -85.000 & 40.000 & 40.000 & 40.000 & 40.000 & & & & & & \\
& -28.000 & 19.200 & 19.200 & 19.200 & 19.200 & 19.200 & & & & & \\
& -22.000 & 6.290 & 6.290 & 6.290 & 6.290 & 6.290 & 6.290 & & & & \\
& -20.000 & 5.000 & 5.000 & 5.000 & 5.000 & 5.000 & 0 & 5.000 & & & \\
-17.500 & 5.000 & 5.000 & 5.000 & 5.000 & 5.000 & 5.000 & & & & \\
& -10.000 & 4.000 & 4.000 & 4.000 & 4.000 & & & & & & \\
& -8.000 & 1.594 & 1.594 & 1.594 & 1.594 & 1.594 & 1.594 & 1.594 & 1.594 & 1.594 & 1.594 \\
& -6.000 & 2.000 & 2.000 & 3.000 & 3.000 & & & & & & \\
& -5.000 & 1.672 & 1.672 & 1.672 & 1.672 & 1.672 & & & & & \\
-1.500 & 300 & 450 & 750 & 750 & 900 & & & & & \\
& -1.000 & 900 & 250 & 10 & 10 & & & & & & \\
-1.000 & 1.000 & 100 & 50 & 50 & & & & & & \\
& -750 & 165 & 165 & 165 & 165 & 165 & 165 & 369 & & & \\
& -620 & 125 & 125 & 125 & 125 & 125 & 125 & 278 & & & \\
& -480 & 113 & 113 & 113 & 113 & 113 & 113 & 262 & & & \\
& -200 & 100 & 100 & 100 & 100 & 100 & 100 & 100 & 100 & 100 & 100 \\
-100 & 20 & 120 & & & & & & & & \\
-5 & 5 & 20 & & & & & & & & \\
\hline-120.000 & -111.155 & 33.484 & 260.199 & 261.069 & 261.069 & 118.159 & 13.387 & 17.603 & 1.694 & 1.694 & 1.694 \\
\hline
\end{tabular}

Fonte: Elaborado pelo autor.

Tabela 6. Resumo dos resultados.

\begin{tabular}{lccc}
\hline & \multicolumn{1}{c}{ Heurística } & H3 & H1 \\
\hline Número de melhores resultados & $6 \mathrm{em} 38$ & $33 \mathrm{em} 38$ & $37 \mathrm{em} 38$ \\
Percentual de melhores resultados & 15,8 & 86,8 & 97,4 \\
Redução percentual média do investimento original & 27,6 & 37,6 & 37,8 \\
Tempo médio (s) & 315 & 2 & 238 \\
\hline
\end{tabular}

Fonte: Elaborado pelo autor. 


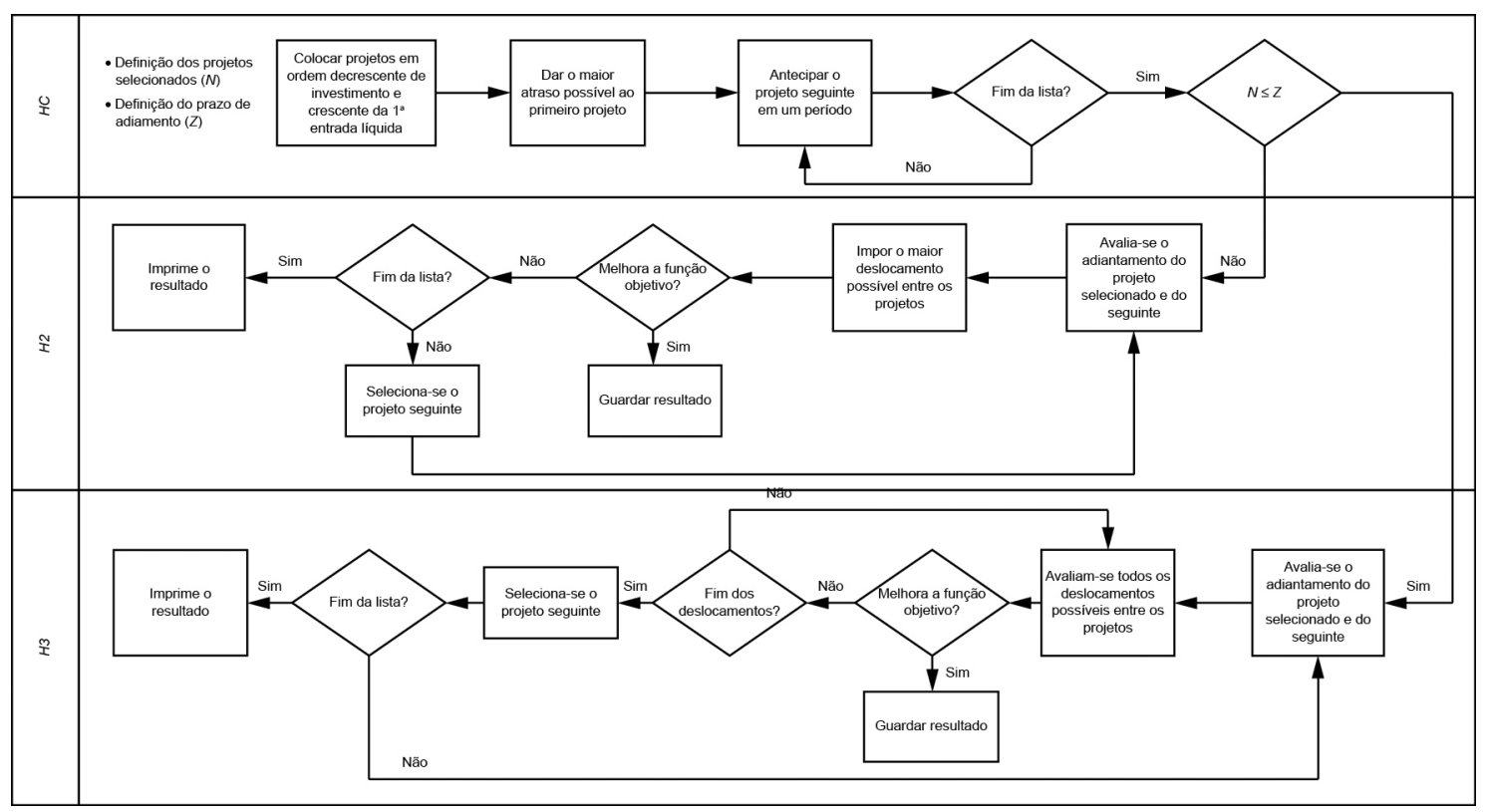

Figura 4. Fluxograma da integração das heurísticas. Fonte: Elaborado pelo autor.

apresenta o resultado da sequenciação dos projetos do grupo 20 (parte 1). A Tabela 6 mostra um resumo dos resultados encontrados.

\section{Considerações finais}

O Capital Circulante Líquido, que tem também outras denominações como Capital de Giro e Ativo Circulante, representa o valor dos recursos aplicados pela empresa para movimentar seu ciclo operacional (LEMES JÚNIOR; RIGO; CHEROBIN, 2005). Entre os objetivos desta área da administração financeira está a redução dos custos de financiamento do ciclo operacional.

Embora com focos e posições distintas na administração financeira, este trabalho relacionou os conceitos de Capital Circulante Líquido (curto prazo) e Orçamento de Capital (longo prazo), cuja lógica pode ser resumida da seguinte forma: fazer com que os projetos integrantes do orçamento de capital financiem parte dos investimentos previstos para redução do custo total da empresa. Sob esta perspectiva, há criação interna de capital de giro para financiamento dos projetos.

Os resultados encontrados pela aplicação do modelo matemático proposto integrado à ferramenta computacional desenvolvida são expressivos com possibilidades de redução de até $55 \%$ do investimento original previsto. Conforme levantamento feito e devido às características particulares da situação analisada, a heurística criada pode ser considerada inédita em termos de formulação matemática. Além disto, foi introduzido um novo método de busca local denominado de deslocamento orientado de pares $(D O P)$.

Por contribuir na redução dos custos de financiamento, o modelo proposto pode colaborar na melhora da classificação de risco (risco de crédito) de corporações sujeitas a este tipo de avaliação. Nesta linha de raciocínio, uma proposta de trabalho futuro estaria associada à análise dos impactos na classificação de risco devido à sequenciação de projetos de investimento. Como exemplo, conforme Amorim (2013), a Petrobras concluiu em 20/5/2013 a captação de US\$ 11 bilhões em títulos de dívida para financiamento de seus investimentos, avaliados como BBB (baixo risco) pela agência Standard \& Poor's.

Os testes foram executados sobre exemplos teóricos disponíveis na literatura, mas sem prejuízo de qualidade sobre os resultados, pois representam projetos de investimento factíveis. Uma linha proposta para novos estudos seria aplicá-lo sobre estudos de casos reais para avaliar as opiniões dos gestores.

Conforme mostrado na seção 2 , o problema analisado possui uma regra lógica definida para obtenção dos melhores resultados. Esta característica restringe a eficiência de métodos de busca baseados em aleatoriedade. Mesmo assim, outra sugestão para novos estudos seria o desenvolvimento de procedimentos heurísticos e/ou meta-heurísticos (Algoritmos Genéticos, Simulated Annealing) para comparação com os resultados da formulação proposta, sendo cabível, inclusive, a variação do número de datas possíveis de adiamento dos projetos.

Conforme Santos e Pamplona (2002), a falta de evidências empíricas que mostrem a aplicabilidade 
da Teoria de Opções Reais (TOR) na prática parece inibir sua adoção em maior grau. Este trabalho fornece um exemplo prático de aplicação facilitado pelo uso de técnicas heurísticas, contribuindo, desta maneira, na diminuição da lacuna entre a teoria e a prática da TOR.

\section{Referências}

ABENSUR, E. O. Um Modelo Multi-Objetivo de Otimização Aplicado ao Processo de Orçamento de Capital. Gestão \& Produção, v. 19, n. 4, p. 747-758, 2012. http://dx.doi. org/10.1590/S0104-530X2012000400007

ABREU FILHO, J. C. F. et al. Finanças Corporativas. Rio de Janeiro: Editora FGV, 2006.

AMORIM, P. H. Petrobras conclui captação de US\$ 11 bilhões. Conversa Afiada, 2013. Disponível em: <http:// www.conversaafiada.com.br/economia/2013/05/23/ petrobras-conclui-captacao-de-us-11-bilhoes/>. Acesso em: 11 jun. 2013.

BAKER, K. R.; SCUDDER, G. D. Sequencing with Earliness and Tardiness Penalties: a Review. Operations Research, v. 38, n. 1, p. 22-36, 1990. http://dx.doi. org/10.1287/opre.38.1.22

BISKUP, D.; FELDMANN, M. Benchmarks for scheduling on a single machine against restrictive and unrestrictive common due dates. Computers \& Operations Research, v. 28 , n. 8 , p. $787-801,2001$. http://dx.doi.org/10.1016/ S0305-0548(00)00008-3

BRF BRASIL FOODS S.A. - BRF. Relações com Investidores. Disponível em: <http://www.brasilfoods. com/ri/>. Acesso em: 20 abr. 2013.

BRIGHAM, E. F.; GAPENSKI, L. C.; EHRHARDT, M. C. Administração Financeira: Teoria e Prática. São Paulo: Atlas, 2001

COLIN, E. C. Pesquisa Operacional: 170 Aplicações em Estratégia, Finanças, Logística, Produção, Marketing e Vendas. Rio de Janeiro: LTC, 2007.

COMPANHIA VALE DO RIO DOCE - CVRD. Resultados e Informações Financeiras. Disponível em: <http:// www.vale.com/brasil/PT/investors/Paginas/default. aspx/>. Acesso em: 20 abr. 2013.

GITMAN, L. J.; MADURA, J. Administração Financeira: uma Abordagem Gerencial. São Paulo: Pearson Addison Wesley, 2003.

GOLDBARG, M. C.; LUNA, H. P. L. Otimização Combinatória e Programação Linear. Rio de Janeiro: Elsevier, 2005.

HIRSCHFELD, H. Engenharia Econômica e Análise de Custos: Aplicações Práticas para Economistas, Engenheiros, Analistas de Investimentos e Administradores. São Paulo: Atlas, 2009.
HOOGEVEEN, J. A.; VELDE, S. L. Scheduling Around a Small Common Due Date. European Journal of Operational Research, v. 55, n. 2, p. 237-242, 1991. http://dx.doi.org/10.1016/0377-2217(91)90228-N

ITAÚ UNIBANCO S.A. - ITAÚ. Relações com Investidores. Disponível em: <http://ww13.itau.com.br/portalri/index. aspx?idioma=port $>$. Acesso em: 20 abr. 2013.

KLIEMANN NETO, J. F et al. A Gestão de Riscos como Ferramenta para Aumento da Competitividade das Empresas. In: OLIVEIRA, V. F.; CAVENAGHI, V.; MÁSCULO, F. S. (Org.). Tópicos Emergentes e Desafios Metodológicos em Engenharia de Produção: Casos, Experiências e Proposições. Rio de Janeiro: ABEPRO, 2011. p. 151-210.

KOULAMAS, C.; ANTONY, S. R.; JAEN, R. A Survey of Simulated Annealing Applications to Operations Research Problems. Omega, v. 17, n. 6, p. 551-557, 1994.

LEMES JÚNIOR, A. B.; RIGO, C. M.; CHEROBIN, A. P. S. Administração Financeira: Princípios, Fundamentos e Práticas Brasileiras. Rio de Janeiro: Campus, 2005.

OSMAN, J. H.; POTTS, C. N. Simulated Annealing for Permutation Flow-Shop Scheduling. Omega, v. 22, n. 1, p. 41-56, 1989.

ROSS, S. A.; WESTERFIELD, R. W.; JAFFE, J. F. Administração Financeira. São Paulo: Atlas, 2002.

SABOIA, P. L. J. Problema Integrado de Dimensionamento e Sequenciamento de Lotes de Produção em uma Fábrica de Produtos de Higiene Pessoal. 2010. 147 f. Trabalho de Conclusão de Curso (Graduação em Engenheiro de Produção)-Escola Politécnica, Universidade de São Paulo, São Paulo, 2010.

SAMANEZ, C. P. Engenharia Econômica. São Paulo: Pearson Prentice Hall, 2009.

SANTOS, E. M.; PAMPLONA, E. O. Teoria de Opções Reais: Aplicação em Pesquisa e Desenvolvimento (P\&D). In: ENCONTRO BRASILEIRO DE FINANÇAS, 2., 2002, Rio de Janeiro. Anais... Rio de Janeiro, 2002.

SOUZA, J. S.; KLIEMANN NETO, F. J.; FILOMENA, T. P. Definição de Portfolio de Investimentos em uma Empresa usando Análise Multicriterial. Revista Produção On-Line, v. 10, n. 1, p. 168-196, 2010.

TAHA, H. A. Pesquisa Operacional. São Paulo: Pearson Prentice Hall, 2008.

TOSO, E. A. V.; MORABITO, R. Otimização no Dimensionamento e Sequenciamento de Lotes de Produção: Estudo de Caso numa Fábrica de Rações. Gestão \& Produção, v. 12, n. 2, p. 203-217, 2005. http://dx.doi.org/10.1590/S0104-530X2005000200006

TRIGEORGIS, L. Real Options and Interactions with Financial Flexibility. Financial Management, v. 22, n. 3, p. 202-224, 1993. http://dx.doi.org/10.2307/3665939 
